\title{
Transcranial electrical motor evoked potentials as a prognostic indicator for motor recovery in stroke patients
}

\author{
M Dominkus, W Grisold, V Jelinek
}

\begin{abstract}
Transcranial electrical motor evoked potentials (MEP) were examined in 33 patients within three days after stroke. Normal values for MEP and motor central conduction time (CCT) were obtained in 46 healthy controls whose MEPs were evaluated during slight voluntary muscle contraction and at rest. Two months later 23 patients were re-examined clinically and electrophysiologically. Motor function change was correlated with MEP results. Two months after stroke the patients with normal or prolonged CCT had an improved motor function compared with those with absent CCT. MEP may be a valuable prognostic indicator in the acute stage of paralytic stroke for recovery of motor function.
\end{abstract}

The development of a non-invasive method of transcranial electric stimulation by Merton and Morton in $1980^{1-3}$ has permitted electrophysiological examination of the central motor pathways for clinical purposes. Motor central conduction time (CCT) can be calculated by the difference of latency after cortical and cervical spinal stimulation. ${ }^{4}$ Recent studies have attempted to correlate the prognostic value of somatosensory and motor evoked potentials in coma ${ }^{56}$ and some neurological diseases. ${ }^{7-13}$ Patients with stroke and hemiplegia have also received attention. ${ }^{14-16}$ The value of motor evoked potentials (MEP) compared with somatosensory evoked potentials (SEP) in predicting functional recovery in stroke patients has been discussed previously. ${ }^{16}$ Electrical transcranial and cervical spinal stimulation was used in a group of 33 patients suffering from acute stroke. The first examination was carried out within three days after stroke. All patients had severe motor deficits or hemiplegia. A motor function index (MFI) was used to score disability. ${ }^{1718}$ Two months later 23 patients were re-examined clinically using the same electrophysiological and scoring procedures and results for motor recovery were compared.

\section{Patients and methods}

Sixteen men and 17 women with a mean age of 69 years (range 44-83 years) were examined within three days after stroke and again two months later. Motor function was obtained by the Demeurisse motor function index (MFI). ${ }^{17}$ This index quantifies voluntary motor function of the upper and lower limbs. By examination of a limited number of movements, selected by a statistical procedure, ${ }^{18}$ an overall indication of the motor deficit on the paretic side can be defined. In the upper extremity the scores of shoulder flexion, elbow flexion and hand grip are converted into their weighted values. ${ }^{17}$ Their average'gives an index expressing (in percentages) the motor function of the upper limb. MFI ranges from 0 to $100 \%$. Complete hemiplegia is rated $0 \%$, whereas full movement and strength scores $100 \%$. The MFI of the upper limbs was compared with CCT values recorded from the biceps brachii muscle and from the abductor pollicis brevis muscle in 20 patients. The biceps brachii muscle was selected because flexion of the elbow, unlike the complex movements mentioned above, can be easily obtained and relies mostly on biceps muscle strength. Only voluntary flexion movements of the elbow were accepted for the MFI.

The electrical stimulation of the motor cortex was delivered by an isolated stimulator (Digitimer D 180) with condensor discharges of $50 \mu \mathrm{s}$ and maximum voltage of $750 \mathrm{~V}$. Anodal cortical stimulation was performed with subcutaneously positioned commercially available EEG-needle electrodes, positioned on vertex and over motor hand area at a distance of $7 \mathrm{~cm}$ on a line to the porus acusticus externus. Muscle action potentials (MAP) were recorded from the biceps brachii muscle with surface electrodes with an uptake area of $1 \mathrm{~cm}^{2}$. In some cases with low amplitudes conventional concentric EMG needle electrodes were used for recording. The stimulator output was increased until no further increase of MAP could be observed. A conventional four channel electromyograph (Disa 1500), set with a bandpass of $2 \mathrm{~Hz}$ to 10 $\mathrm{kHz}$ was used for recording. Cervical stimulation was performed in a median position with the cathode applied in intervertebral space C5/C6. The anode was positioned $6 \mathrm{~cm}$ rostrally. In addition, the latency was measured from the brachial plexus (Erb's point) to exclude peripheral nerve conduction delays. Cortical stimulation was performed with a stimulus output of $70-100 \%$, C6 stimulation with an output of $50-80 \%$ and stimulation at Erb's point with $30-50 \%$. Normal values for cortical, spinal and plexus stimulation were obtained in 46 healthy volunteers $(21$ men, 25 women, mean age: 66 years, range: $20-84$ 
Table 1 Normal values for MAP latencies for biceps brachii muscle and abductor pollicis brevis ( $A P B$ ) muscle evoked by cortical, cervical and plexus brachialis stimulation during slight voluntary contraction and at rest $(n=46)$. Central motor conduction time (CCT) was calculated from the difference between cortical and cervical latency

\begin{tabular}{|c|c|c|c|c|}
\hline \multirow[b]{2}{*}{ Muscle stimulated } & \multicolumn{3}{|c|}{ Stimulation site } & \multirow[b]{2}{*}{$C C T R / C$} \\
\hline & Cortex $R / C$ & $C 5 / 6(C 7 / T 1)$ & $E r b$ & \\
\hline $\begin{array}{l}\text { Biceps brachii } \\
\text { APB }\end{array}$ & $\begin{array}{c}10 \cdot 5 / 11 \cdot 8 \\
0 \cdot 8 / 1 \cdot 2 \\
19 \cdot 1 / 20 \cdot 2 \\
1 \cdot 1 / 0.9\end{array}$ & $\begin{array}{r}6 \cdot 4 \\
0.4 \\
14 \cdot 3 \\
0.6\end{array}$ & $\begin{array}{r}4.9 \\
0.6 \\
12 \cdot 8 \\
0.5\end{array}$ & $\begin{array}{l}4 \cdot 1 / 5.4 \text { Mean } \\
0.8 / 0.8 \mathrm{SD} \\
4.8 / 5.9 \text { Mean } \\
0.7 / 0.8 \mathrm{SD}\end{array}$ \\
\hline
\end{tabular}

Cortex C: Stimulation during slight muscle contraction.

Cortex R: Stimulation at rest.

CCTC: Central motor conduction time (contracted).

CCTR: Central motor conduction time (relaxed).

Table 2 Clinical and electrophysiological features of 33 patients after stroke years) at rest and during slight voluntary muscle contraction (table 1 ).

MEP latencies are directly dependent on body size, ${ }^{19}$ whereas the length of the intracranial motor pathways are assumed to be relatively constant in adults analogous to somatosensory pathways. ${ }^{20}$ For this reason CCT values were used for further calculation. As voluntary contraction of the target muscle leads to shortening of CCT by $2-4 \mathrm{~ms}^{21}$ compared to the rested state, hemiplegic patients were asked to innervate also the healthy extremity to achieve the shortest latency possible.

\begin{tabular}{|c|c|c|c|c|c|c|c|c|c|c|c|c|c|c|}
\hline & & & & & Initia & -follow & $p$ examinati & & & & & & & \\
\hline & & & & & $10-3$ & ays) & & & & $160-6$ & 9 days) & & & \\
\hline Pati & ts/age & & $C / T$ Diagnosis—size $(S / M / L)$ & & $C C T$ & $C C T$ & ССТTHX & CCTTH & $M F I$ & $C C T$ & $C C T$ & ССTTHX & CCTTH & $M F I$ \\
\hline $\begin{array}{l}1 \\
2 \\
3 \\
4 \\
5 \\
6\end{array}$ & $\begin{array}{l}59 \\
77 \\
44 \\
60 \\
74 \\
69\end{array}$ & $\begin{array}{l}R \\
R \\
R \\
\text { L } \\
\text { L } \\
\text { L }\end{array}$ & $\begin{array}{l}\text { posterior } \\
\text { capsular } \\
\text { capsular, bas ggl } \\
\text { capsular } \\
\text { parietal } \\
\text { temporo parietal }\end{array}$ & $\begin{array}{l}\text { L } \\
\text { L } \\
\text { L } \\
\text { S } \\
\text { L } \\
\text { S }\end{array}$ & $\begin{array}{l}4 \cdot 1 \\
4 \cdot 9 \\
5 \cdot 2 \\
5 \cdot 2 \\
5 \cdot 4 \\
5 \cdot 6\end{array}$ & $\begin{array}{l}5 \cdot 0 \\
4 \cdot 5 \\
4 \cdot 1 \\
5 \cdot 4 \\
4 \cdot 2 \\
5 \cdot 2\end{array}$ & $\begin{array}{l}\mathrm{nm} \\
\mathrm{nm} \\
\mathrm{nm} \\
6 \cdot 1 \\
5 \cdot 9 \\
\mathrm{~nm}\end{array}$ & $\begin{array}{l}\mathrm{nm} \\
\mathrm{nm} \\
\mathrm{nm} \\
5 \cdot 6 \\
5 \cdot 1 \\
\mathrm{~nm}\end{array}$ & $\begin{array}{r}92 \\
75 \\
84 \\
75 \\
0 \\
75\end{array}$ & $\begin{array}{l}+ \\
+ \\
4 \cdot 8 \\
4 \cdot 2 \\
5 \cdot 5 \\
4 \cdot 6\end{array}$ & $\begin{array}{l}4 \cdot 1 \\
3 \cdot 7 \\
4 \cdot 6 \\
4 \cdot 3\end{array}$ & $\begin{array}{l}\mathrm{nm} \\
6 \cdot 2 \\
5 \cdot 8 \\
\mathrm{~nm}\end{array}$ & $\begin{array}{l}\mathrm{nm} \\
6 \cdot 1 \\
5 \cdot 3 \\
\mathrm{~nm}\end{array}$ & $\begin{array}{l}92 \\
92 \\
35 \\
83\end{array}$ \\
\hline $\begin{array}{r}7 \\
8 \\
9 \\
10 \\
11 \\
12 \\
13 \\
14 \\
15 \\
16 \\
17 \\
18 \\
19\end{array}$ & $\begin{array}{l}55 \\
83 \\
83 \\
79 \\
87 \\
55 \\
78 \\
58 \\
81 \\
59 \\
64 \\
83 \\
82\end{array}$ & $\begin{array}{l}\text { LF } \\
\text { L } \\
\text { R } \\
\text { L } \\
\text { L } \\
\text { L } \\
\text { L } \\
\text { R } \\
\text { L } \\
\text { R } \\
\text { R } \\
\text { R } \\
\text { L }\end{array}$ & $\begin{array}{l}\text { bas ggl } \\
\text { capsular } \\
\text { capsular } \\
\text { capsular } \\
\text { temporo parietal } \\
\text { capsular } \\
\text { capsular } \\
\text { capsular } \\
\text { temporo parietal } \\
\text { temporo parietal } \\
\text { capsular } \\
\text { temporo occipital } \\
\text { parietal, } R \text { frontal }\end{array}$ & $\begin{array}{l}M \\
S \\
L \\
L \\
M \\
S \\
M \\
S \\
S \\
L \\
M \\
L \\
M\end{array}$ & $\begin{array}{r}6 \cdot 6 \\
7 \cdot 0 \\
7 \cdot 3 \\
7 \cdot 4 \\
7 \cdot 4 \\
8 \cdot 2 \\
8 \cdot 6 \\
8 \cdot 6 \\
9 \cdot 4 \\
9 \cdot 4 \\
10 \cdot 2 \\
10 \cdot 4 \\
10 \cdot 7\end{array}$ & $\begin{array}{l}5 \cdot 0 \\
4 \cdot 1 \\
4 \cdot 8 \\
5 \cdot 6 \\
3 \cdot 8 \\
4 \cdot 0 \\
4 \cdot 9 \\
8 \cdot 0 \\
4 \cdot 6 \\
4 \cdot 0 \\
3 \cdot 8 \\
9 \cdot 2 \\
3 \cdot 4\end{array}$ & $\begin{array}{l}\mathrm{nm} \\
\mathrm{nm} \\
\mathrm{nm} \\
8 \cdot 0 \\
6 \cdot 1 \\
\mathrm{~nm} \\
\mathrm{~nm} \\
5 \cdot 3 \\
\overline{-} \\
\overline{8 \cdot 5} \\
\overline{\mathrm{nm}}\end{array}$ & $\begin{array}{l}\mathrm{nm} \\
\mathrm{nm} \\
\mathrm{nm} \\
6 \cdot 1 \\
5 \cdot 8 \\
\mathrm{~nm} \\
\mathrm{~nm} \\
5 \cdot 5 \\
\frac{6 \cdot 5}{4 \cdot 9} \\
\frac{\mathrm{nm}}{\mathrm{nm}}\end{array}$ & $\begin{array}{r}11 \\
11 \\
33 \\
33 \\
23 \\
0 \\
9 \\
0 \\
37 \\
37 \\
25 \\
0 \\
9\end{array}$ & $\begin{array}{c}+ \\
5 \cdot 6 \\
5 \cdot 3 \\
5 \cdot 2 \\
+ \\
6 \cdot 8 \\
6 \cdot 4 \\
5 \cdot 0 \\
+ \\
6 \cdot 5 \\
4 \cdot 4 \\
+ \\
15 \cdot 2\end{array}$ & $\begin{array}{l}4 \cdot 2 \\
4 \cdot 9 \\
5 \cdot 4 \\
\\
4 \cdot 9 \\
4 \cdot 6 \\
4 \cdot 0 \\
\\
4 \cdot 0 \\
3 \cdot 9 \\
\end{array}$ & $\begin{array}{l}\mathrm{nm} \\
\mathrm{nm} \\
5 \cdot 8 \\
\\
\mathrm{~nm} \\
\mathrm{~nm} \\
5 \cdot 6 \\
\\
6 \cdot 7 \\
5 \cdot 4 \\
\mathrm{~nm}\end{array}$ & $\begin{array}{l}\mathrm{nm} \\
\mathrm{nm} \\
5.9 \\
\mathrm{~nm} \\
\mathrm{~nm} \\
5.5 \\
5.8 \\
5.0 \\
\mathrm{~nm}\end{array}$ & $\begin{array}{l}33 \\
69 \\
59 \\
\\
60 \\
59 \\
69 \\
\\
60 \\
75 \\
\\
31\end{array}$ \\
\hline $\begin{array}{l}20 \\
21 \\
22 \\
23 \\
24 \\
25 \\
26 \\
27 \\
28 \\
29 \\
30 \\
31 \\
32 \\
33\end{array}$ & $\begin{array}{l}55 \\
67 \\
77 \\
57 \\
64 \\
59 \\
67 \\
80 \\
49 \\
66 \\
72 \\
73 \\
61 \\
64\end{array}$ & $\begin{array}{l}\text { L } \\
\mathbf{R} \\
\mathbf{R} \\
\mathbf{R} \\
\mathbf{R} \\
\mathbf{L} \\
\mathbf{L} \\
\mathbf{L} \\
\mathbf{R} \\
\mathbf{R} \\
\mathbf{L} \\
\mathbf{R} \\
\mathbf{R} \\
\mathbf{R}\end{array}$ & $\begin{array}{l}\text { capsular, R occipital } \\
\text { capsular, basal ggl } \\
\text { capsular } \\
\text { temporo parietal } \\
\text { L mult embol inf } \\
\text { temporo parietal } \\
\text { posterior } \\
\text { cereb peduncle } \\
\text { temporo parietal } \\
\text { capsular } \\
\text { temporo parietal } \\
\text { capsular } \\
\text { temporo parietal } \\
\text { capsular }\end{array}$ & $\begin{array}{l}\text { L } \\
\text { L } \\
M \\
\text { L } \\
\text { L } \\
\text { L } \\
\text { L } \\
\text { M } \\
\text { L } \\
\text { S } \\
\text { L } \\
\text { M } \\
\text { S } \\
\text { L }\end{array}$ & $\begin{array}{l}= \\
= \\
= \\
= \\
= \\
= \\
=\end{array}$ & $\begin{array}{l}4 \cdot 9 \\
4 \cdot 1 \\
8 \cdot 9 \\
- \\
3 \cdot 6 \\
3 \cdot 0 \\
3 \cdot 7 \\
4 \cdot 5 \\
4 \cdot 0 \\
6 \cdot 2 \\
4 \cdot 2 \\
5 \cdot 5\end{array}$ & $\begin{array}{l}\overline{\mathrm{nm}} \\
\overline{-} \\
\overline{-} \\
\overline{\mathrm{nm}} \\
\overline{-} \\
\overline{5 \cdot 2} \\
\frac{\mathrm{nm}}{8 \cdot 2}\end{array}$ & $\begin{array}{l}5 \cdot 3 \\
\mathrm{~nm} \\
- \\
- \\
\overline{5 \cdot 3} \\
\mathrm{~nm} \\
\overline{5 \cdot 1} \\
5 \cdot 4 \\
4 \cdot 9 \\
\mathrm{~nm} \\
4 \cdot 8 \\
5 \cdot 6\end{array}$ & $\begin{array}{r}0 \\
0 \\
0 \\
0 \\
0 \\
0 \\
0 \\
9 \\
9 \\
9 \\
11 \\
20 \\
20 \\
25\end{array}$ & $\begin{array}{l}\overline{-} \\
+ \\
\overline{-} \\
7 \cdot 7 \\
7 \cdot 5 \\
\frac{+}{6 \cdot 9} \\
\frac{+}{+}\end{array}$ & $\begin{array}{l}4 \cdot 8 \\
4 \cdot 1 \\
- \\
-3 \cdot 8 \\
3 \cdot 2 \\
- \\
4 \cdot 6 \\
4 \cdot 3\end{array}$ & $\begin{array}{l}\overline{\mathrm{nm}} \\
\overline{-} \\
\overline{8 \cdot 1} \\
7 \cdot 8 \\
- \\
\overline{-} \\
-\end{array}$ & $\begin{array}{l}5.5 \\
\mathrm{~nm} \\
- \\
\overline{5.5} \\
4.9 \\
\overline{5.6} \\
- \\
4.9\end{array}$ & $\begin{array}{r}0 \\
0 \\
0 \\
0 \\
0 \\
9 \\
46 \\
\\
9 \\
37 \\
11 \\
\\
20\end{array}$ \\
\hline
\end{tabular}

Table 2 shows clinical characteristics of examined patients. Site and size of cerebral lesion are compared with CCT-findings in acute stage and two months later. CCT of undamaged hemisphere is listed for both examinations.

CCTX: central motor conduction time (ms) to biceps brachii muscle of damaged hemisphere during voluntary contraction.

CCT: central motor conduction time (ms) to biceps brachii muscle of undamaged hemisphere during voluntary contraction.

CCTHX: central motor conduction time $(\mathrm{ms})$ to thenar (abductor poll brevis muscle) of undamaged hemisphere during voluntary contraction.

CCTTH: central motor conduction time (ms) to thenar muscle of undamaged hemisphere during voluntary contraction.

MFI: motor function index of upper limb $(0-100)$.

nm: not measured.

$+:$ died before control

-: no EMG response after cortical stimulation could be obtained.

$\mathrm{R}$ : right side.

L: left side.

cereb: cerebral.

Bas ggl:basal ganglia.

Mult embol inf: multiple embolic infarctions.

Size: CT lesions were grouped into small $(S)<0.5 \mathrm{~cm}$, medium $(M)<2.5 \mathrm{~cm}$, and large lesions $(\mathrm{L})>2.5 \mathrm{~cm}$ diameter.

Table 3 Neuropathological correlations in deceased patients $(n=8 / 10)$

\begin{tabular}{|c|c|c|c|c|}
\hline Patient no & Age & CT Diagnosis & $\operatorname{Size}(S / M / L)$ & Neuropathological lesion \\
\hline 2 & 77 & R capsular & $\mathbf{L}$ & \multirow{5}{*}{$\begin{array}{l}\text { right thalamic infarction, subarachnoid } \\
\text { haemorrhage } \\
\text { diffuse anoxic brain damage } \\
\text { infarction left pontine peduncle } \\
\text { haemorrhage brain infarction, right } \\
\text { temporal lobe and right thalamus, } \\
\text { infarction right pontine peduncle and right } \\
\text { paramedian pons } \\
\text { infarction right medial thalamus. Bilateral } \\
\text { lacunar state } \\
\text { brain death, no intact brain tissue } \\
\text { cystic lesion right capsular region, lacunar } \\
\text { state in pons and mesencephalon } \\
\text { acute haemorrhage right basal ganglia }\end{array}$} \\
\hline $\begin{array}{r}7 \\
15 \\
18\end{array}$ & $\begin{array}{l}55 \\
81 \\
83\end{array}$ & $\begin{array}{l}\text { LR basal ganglia } \\
\text { L temporo-parietal } \\
\text { R temporo-occipital }\end{array}$ & $\begin{array}{l}M \\
S \\
L\end{array}$ & \\
\hline 22 & 77 & $\mathbf{R}$ capsular & $\mathbf{M}$ & \\
\hline $\begin{array}{l}27 \\
31\end{array}$ & $\begin{array}{l}80 \\
73\end{array}$ & $\begin{array}{l}\text { L pedunc cerebr } \\
R \text { capsular }\end{array}$ & $\begin{array}{l}\mathbf{M} \\
\mathbf{M}\end{array}$ & \\
\hline 33 & 64 & $\mathbf{R}$ capsular & $\mathbf{L}$ & \\
\hline
\end{tabular}

Table 3 Eight patients had a neuropathological examination. The site of lesion correlated with CT findings in most cases. In patient 27 brain death occurred due to circulatory causes after evaluation of MEPs. 
Figure 1 Median MFI values of patients with normal, prolonged and absent CCTs are shown in the first (white) columns. Increase of the MFI values at follow up examination two months later are shown in the hatched columns.

Median motor function index in acute stage $(N=$ 33) and at follow up examination two months later $(N=23)$

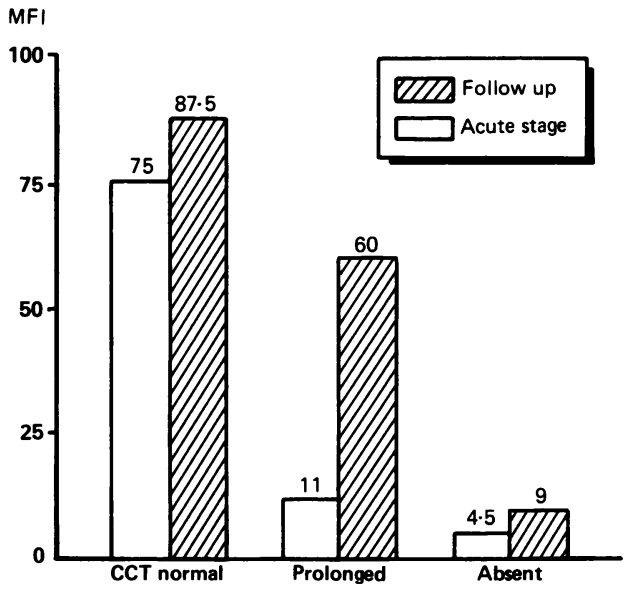

As the facilitation is assumed to occur at a spinal level ${ }^{22}$ it can be obtained by voluntary contraction of a limb muscle ipsilateral to cortical stimulation. ${ }^{23}$

MAP amplitudes varied from 0.5 to $4 \mathrm{mV}$ on the paretic side. The amplitudes were variable and less suitable for quantification than the latencies. ${ }^{78}$ CCTs were considered prolonged if they exceeded the normal mean by more than two standard deviations $(5 \cdot 7 \mathrm{~ms})$. CCTs were considered absent if two consecutive brain stimuli with maximum voltage provoked no measureable EMG response. CCT results were grouped into three categories: normal, prolonged or absent. The CCT values were compared to MFI statistically with the Wilcoxon-test.

$$
\text { 0-3 days after stroke } \quad 60-69 \text { days after stroke }
$$

\section{Figure 2}

Electromyographic responses recorded from the left and right biceps brachii muscle in acute stage of stroke and at follow up two months later.

Patient 17: the left biceps brachii muscle showed a weak and delayed MAP initially, two months later $M A P$ resembled the healthy (right) side (MFI rose from 25 to 75 ). Patient 19: the primarily delayed MAP (right) deteriorated further at control examination, clinically slight improvement. * Patient 25: initially absent MAP. Two months later prolonged latency ( MFI 0-9) clinically slight improvement. Patient 26: initially absent MAP. Two months Pat 26 later mild prolongation, clinically good improvement (MFI O46).*

Patient 29: initially no $M A P$, nearly normal latency at control examination (MFI 937). $\star$

* partially concentric needle electrode recordings.

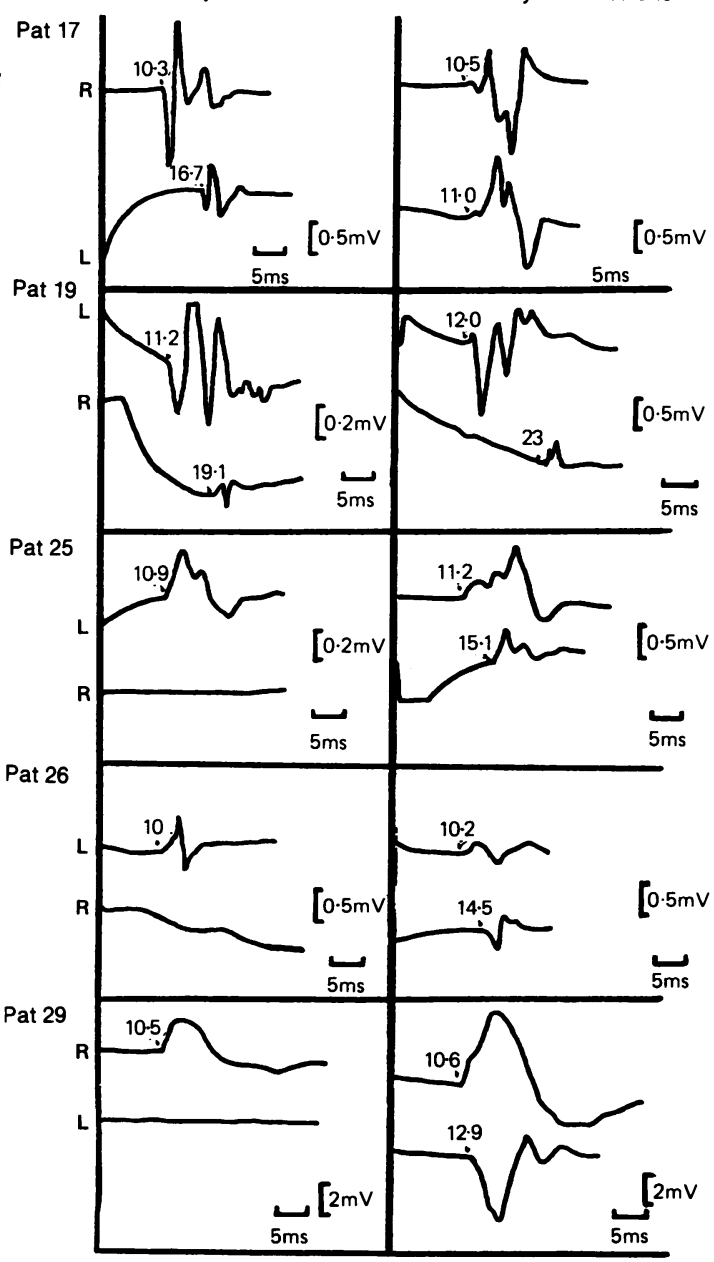

In all patients cerebral vascular lesions were confirmed by cranial computerised tomography (CT). The site of the lesions was categorised into cortical and capsular. Only one patient had a peduncular infarction. Ten patients died within the observation period, eight patients were examined neuropathologically by standard methods (table 3 ).

\section{Results}

Patients were categorised according to CCT values: normal Pat 1-6, prolonged Pat 7-19 or absent Pat 20-33 (see table 2).

\section{(a) Normal CCT}

Six patients had normal CCTs at initial examination despite motor deficit. Their median MFI was 75 (range 0-92). In two patients of this group the CCT was also measured to APB and revealed also normal values. Two months later CCT remained normal in four patients whose median MFI had increased to 87.5 (range 35-92). The change in MFI values was not significant.

\section{(b) Prolonged CCT}

Prolonged CCTs were seen in 13 patients. The range of prolonged CCTs was $6,6-15,2 \mathrm{~ms}$. On first examination this group of patients had a median MFI of 11 (range 0-37). Two months later nine patients were re-examined: most showed an improvement of CCT values to nearly normal values (patient 8, 9, 14, 17 (fig 2)). Only one patient's CCT deteriorated compared to the initial examination (patient 19, fig 2). Clinically, this group showed a major improvement, indicated by an increase of MFI to a median value of 60 (range 31-75), which was statistically significant $(\mathrm{p}=0.007)$.

\section{(c) Absent CCT}

In 14 patients, MEPs could not be recorded in the acute stage. Their median MFI was 4.5 (range 0-25). Two months later, 10 patients were re-examined. In seven patients CCTs remained absent. In three patients of this group who had initially absent CCTs, prolonged CCTs could be recorded after two months. These patients showed an increase in MFI (patient 25, 26 and 29, fig 2). The median MFI for this group, however, increased poorly to nine (range 0-46) and almost all patients in this sample showed no or only very little clinical improvement ( $p=0.25$ ) (see fig 1 ).

CT scan results are listed in table 2. No difference in the distribution of lesions was detected

Necropsy results were available in eight patients (table 3 ).

\section{Discussion}

The measurement of CCT latencies with transcranial motor evoked potentials is a suitable tool for the assessment of lesions of central motor pathways. ${ }^{5-15}$ Our results suggest a correlation of CCT latencies in stroke patients with recovery of motor function and are 
superior to other electrophysiological methods (SEP), recently shown by Macdonnel et al. ${ }^{16}$ However, the use of MEP for prognostic purposes towards motor recovery is limited to the acute stage. Compared with the results of Berardelli et al, ${ }^{14}$ who investigated a group of chronic stroke patients (1-22 months after stroke), we found a higher clinical significance of this examination. Our findings define a group of patients with initially prolonged CCTs. Patients with initially prolonged CCTs, and poor motor function at the first examination have a good motor recovery two months later.

Until recently the mechanisms for a prolongation of CCTs have not been clarified. It is unlikely that the delay in CCT can be attributed to an interruption or degeneration of corticospinal fibres ${ }^{2}$ as CCT values decrease with motor improvement. Thompson et al ${ }^{15}$ argue that delayed responses may be either caused by slowing of conduction of large diameter fibres in pyramidal tract or that the cortical stimulus may be only capable of recruiting small slowly conducting motor neurons. Thus the prolongation of CCTs may be caused by temporal dispersion of excitatory postsynaptic potentials and create an apparent delay in CCT. Another possible explanation for the delayed CCTs may be given by a transient conduction block analogous to neuropraxia in the peripheral nervous system. Our data are supported by the clinical observation, that severe disabilities in acute stroke can occur despite minor structural lesions as seen by neuroradiological methods. The concept of focal conduction block in the central nervous system, however, is speculative, since, to the best of our knowledge, no relevant electrophysiologic data in this context are available.

1 Merton PA, Morton HB. Electrical stimulation of human motor and visual cortex through the scalp. $J$ Physiol 1980;305:9-10.

2 Merton PA, Morton HB. Stimulation of the cerebral cortex in the intact human subject. Nature 1989;285:227.
3 Merton PA, Morton HB, Hill DK, Marsden CD. Scope of a technique for electrical stimulation of human brain, spinal technique for electrical stimulation of hum

4 Marsden CD, Merton PA, Morton HB. Percutaneous stimulation of spinal cord and brain; pyramidal tract conduction velocities in man. $J$ Physiol 1982;328:6

5 Dominkus M, Grisold W, Jelinek V, Nobis H, Rücker F. Transkraniell motorisch evozierte potentiale in der'intensivmedizin. Intensivbehandlung 1988;13 Nr 3:118-22.

6 Zentner J, Ebner A. Prognostic value of somatosensory- and motor-evoked potentials in patients with a non-traumatic
coma. Eur Arch Psychiatr Neurol Sci 1988:237:184-7.

7 Cowan JMA, Dick JPR, Day BL, Rothwell JC, Thompson PD, Marsden CD. Abnormalities in central motor pathway conduction in multiple sclerosis. Lancet 1984;ii: way-7.

8 Mills KR, Murray MF. Corticospinal tract conduction time in multiple sclerosis. Ann Neurol 1985;18:601-5.

9 Rossini PM, Caramia MD, Zarola F. Mechanisms of nervous propagation along central motor pathways: nonnervous propagation along central motor pathways: noninvasive evaluation in healthy subjects and in patients

10 Swash M, Snooks S. Motor conduction velocity in the human spinal cord. $J$ Physiol 1985;360:50

11 Hugon J, Lebeau M, Tabaraud F, et al. Central motor conduction in motor neuron disease. Ann Neurol 1987;22:544-6.

12 Ingram DA, Swash M. Central motor conduction is abnormal in motor neuron disease. J Neurol Neurosurg Psychiatry 1987;50:159-66.

13 Thompson PD, Day BL, Rothwell JC, Dick JPR, Cowan JMA, Marsden CD. Central motor conduction in JMA, Marsden CD. Central motor conduction in neurological disea

14 Berardelli A, Inhilleri M, Manfredi M, Zamponi A, Cecconi $\mathrm{V}$, Dolce G. Cortical and cervical stimulation after hemispheric infarction. J Neurol Neurosurg Psychiatry 1987;50:861-5

15 Thompson PD, Day BL, Rothwell JC, et al. The interpretation of electromyographic responses to electrical stimulation of the motor cortex in diseases of the upper moto neurone. J Neurol Sci 1987;80:91-110.

16 Macdonnel RAL, Donnan GA, Bladin PF. A comparison of somatosensory evoked and motor evoked potentials in stroke. Ann Neurol 1989;25:68-73.

17 Demeurisse G, Demol O, Robaye E. Motor evaluation in vascular hemiplegia. Eur Neurol 1980;19:382-9.

18 Hotelling J. Analysis of a complex of statistical variables into principal components. J Educ Psychol 1933;24:417-41, 498-520.

19 Meyer BU, Benecke R, Göhmann M, Zipper S, Conrad B. Möglichkeiten und Grenzen der Bestimmung zentraler motorischer Leitungszeiten beim Menschen. $Z E E G$ EMG 1987;18:165-72.

20 Desmedt JE, Cheron G. Spinal and far-field components of human somatosensory evoked potentials to posterior tibia nerve. Electroencephalogr Clin Neurophysiol 1983;56: 635-51.

21 Day BL, Dick JPR, Marsden CD, Thompson PD. Differences between electrical and magnetic stimulation of the human brain. J Physiol 1986;378:36.

22 Berardelli A, Cowan JMA, Day BL, Dick J, Rothwell JC. The site of facilitation of the response to cortical stimulation during voluntary contraction in man. $J$ Physiol tion during

23 Cowan J, Day BL, Marsden CD, Rothwell JC. Evidence for an ipsilateral corticospinal pathway to forearm muscles in man. J Physiol 1983;343:1 14-5. 